\title{
The Management of Kindergarten Students of Little Koala Montessori Karawaci Tangerang
}

\author{
Debby Andriany ${ }^{1}$, Totok Amin Soefijanto ${ }^{2}$, Mochamad Wahyudi ${ }^{3}$ \\ ${ }^{1}$ Doctoral Program, Education Management, Universitas Negeri Jakarta Indonesia \\ Masters Practitioner Tester Management of University Esa Unggul, Indonesia \\ ${ }^{2}$ Lecturer, Universitas Negeri Jakarta, Indonesia \\ ${ }^{3}$ Lecturer, Universitas Negeri Jakarta, Indonesia
}

\begin{abstract}
This research aims to analyze the process of management of the students. Research was conducted at the Kindergarten Little Koala Montessori Karawaci Tangerang. Methods used the case study method by using a qualitative approach. The results showed, (1) analyzed the need for class capacity, student and teacher ratios, planned new online learner acceptance, interest and talent search and learner ability through psychological test to explore interest and talent and readiness learning, (2) making and revising the school rules of conduct book applicable to learners and understood by parents, picking up students, and ordering the parent contact book and trying to communicate in it or face-to-face directly outside the teaching hours of teachers with the promise (3) provide counseling services to solve problems in the development of learners, learning difficulties, prepare mental development, and instill confidence, character formation, and the availability of facilities and infrastructure such as books in the central library and mini library, healthy canteen school, computer lab, plant area, pets up a special swimming pool for Little Koala Montessori (4) daily learning reports in daily lesson, weekly study reports aimed at principals, Montessori monthly report cards, and reports from the Education Board and building cooperation with graduates and parents student. Based on the findings, it was concluded that the montessori plus method of effective learning management for learners.
\end{abstract}

Keywords: Management, students, and Little Koala Montessori

\section{Introduction}

The lack of maximum educational services for early age students, especially kindergarten or kindergarten, among others, is caused by the lack of socialization about education for early childhood which is good and directed or precisely tersistem, the role of government in this case the education office, community and people old in early childhood coaching. Little Koala Montessori Karawaci Tangerang Kindergarten comes to provide solutions to these problems.

The researchers raised the study at Little Koala Montessori Karawaci Tangerang Kindergarten because it has a uniqueness that is not owned by schools and includes other Montessori schools. Some of these uniqueness among others; (1) acceptance of new students wave 1 of 2 years before; (2) method montessori applying curriculum exercise of practical life, cultural, sensorial. Math, language plus applying the official curriculum; (3) the deepening of their respective religions (Islam, Catholic, Protestant, Buddhist, Hindu) to religious events such as: district-level hajj manasik, holy quran education park, Christmas and Easter events at city level and other religious activities; (4) introduction of Mandarin; ( 5) the use of good daily English of fellow students, students and teachers and teachers with teachers or among staff; (6) the existence of school cooperation with Association for the International Exchange of Students in Economics and Commerce (AIESEC) one of the UNICEF program which is a volunteer of foreign and domestic students such as Keio University of Japan, Cambridge University, Prasetya Mulya University and University Pelita Harapan, they teach as guest educators at Kindergarten Little Koala Montessori Karawaci Tangerang; (7) excavation of 
interest and talent through extracurricular outside of curricular such as taekwondo, coloring, dancing, futsal, vocals, TPA Al-qur'an education park, shade, morning musings, robotic lego bricks level.

In educating or learning, Kindergarten Little Koala Montessori learners use an integrated curriculum of school curriculum and curriculum montessori, and there is uniqueness in the new online learner acceptance that is two years before the school year because of the interest of quite a lot, Therefore the researchers reasoned to do research on "The Management of Kindergarten Students of Little Koala Montessori Karawaci Tangerang". This study deals with planning, coaching, service, and supervision activities.

\section{Theoretical Background Management}

The management program at this school creates a centered or learner centered classroom, and learners are given the freedom and gain results from every process they learn, aimed at the learning that active learners apply.

According to Armstrong (2014) that management is the act of getting people together to accomplish desired goals. This is in the opinion of Velez (2017) who said that this calls for competent management, which involves clarity in decision-making and coherence in order to adopt the most valuable actions to encourage transformation of the centres and the development of projects for improvement.

In line with this opinion, Marin and Rusu (2015) also said there should be involved at decision, strategic and action levels members of local community, decision makers at local and central level, NGOs, family, school management and each teacher while working individually with its pupils and their parents. As Cheng (2015) says that knowledge management strategy refers to the overall approach an organisatio intends to take to align its knowledge resources and capabilities for enhancing organisational performance.

Knowledge management is needed because in managing the organization needs a deep understanding of the organization is primarily about the main issues that occur within the organization before planning a management. Management is an attempt to identify the cause of the problem in an organization and analyze the effectiveness of the individual so that the goal can be achieved.

\section{Planning}

In essence planning is a human activity done consciously to achieve goals in the future. According to Hill (2015) that an planning is that it can push managers to think outside the box, to anticipate what they might need to do in different situations. Similarly according to Goetsch (2014) that planning is involves developing a written plan that has the following components: an organizational mission, guiding principles, broad strategic objectives, and specific tactics, projects, and activities for achieving the broad objectives.

According to Augier et. al, (2017) that planning is based on the ideas, frameworks, and concepts commonly taught in business schools. Ideally based on a fairly systematic analysis of the business unit's resource profile and task environment, the SWOT framework is commonly applied to extract a strategic platform, and identify the strategic challenges that must be addressed to ensure a profitable future. In line with that opinion. According to Laliene and Liepe (2015) that there are elements of systematic planning process; formulation of the problem, formulation and evaluation of the alternatives, decision making selection of an alternative.

Similarly, in another study conducted in Finland by Laine et. al (2016) found the schools had named goals for action plans in all aspects of the promotion of occupational well-being in schools (worker and work, working conditions, professional competence, working community) and that these goals were mainly realized in the schools in a systematic way.

\section{Coaching}

According to Kolodziejczak (2015) that coaching brings about changes in people's behaviour, stimulates their creativity, coming up with plans and taking actions. Coaching is a method that directs, teaches and trains a person for the purpose of developing certain management skills. Further according to Goetsch (2014) that coaching on the other hand are facilitators of team development and continually improved performance. A study conducted by Carriger (2015) that the role of the instructor in the Montessorian 
approach is one of facilitator, to provide learning-appropriate stimuli that allows the student to develop his or her own potentials and skills.

Besançon et. al, (2015) also said that where differences were found between classical school and Montessori pupils, the Montessori children tended to do better than the others. More recently, Besançon and Lubart also studied the influence of educational methods on the development of children's creativity. Their results indicated that, in general, children attending alternative education systems (Montessori and Freinet in that study) obtained higher performances than children attending traditional schools.

\section{Service}

One of the role in improving the quality of education is the right service for learners. service is part of educational management of learners. According to research results Liu (2015) said that schools can develop good service learning programs for students to participate, especially in groups since peers are one of the major sources of social influence. Teachers should help students understand the meaning of service learning and what they can do.

Similarly, according to Miller, Farkas, and Duncan (2016) that therefore the match between children's characteristics, including prior experiences and needs, and the services offered by Head Start is crucial in determining whether the program is appropriate and successful for a given child. According to Crawford et. $a l$, (2017) that service learning is a 'real-world' training method that differs from traditional practical training because it combines academic goals with community service objectives.

In building a quality school requires a program of human resource learning services. Learning service is a program that must be designed to meet the needs of learners, motivation, and provide the ability of learners in participating in schools and communities.

\section{Controlling}

According to Demanet and Houtte (2014) that perceived control is tantamount to competence or the ability to successfully perform an action and to autonomy, the need to self-initiate and self-regulate. Further according to Berger et. al (2017) that as well as controls that might contribute to classroom chaos, including teachers' years of teaching experience and education.

Similarly, according to Bartholomew et. al (2017) that controlling interpersonal style can be expressed in two different ways: externally controlling and internally controlling. Research conducted by Sheppard et. al, (2015) says that Montessori-based activities have also been applied to improve functioning in other domains, including cognition and activities of daily living, such as feeding. Furthermore, according to Schacter and Booil Jo (2016) that each Montessori "job" communicates clear goals, provides for selfassessment and corrective feedback, and uses manipulatives to learn by doing.

\section{Method of Research}

The methods used in this study are case study methods using a qualitative approach. This case study research method is used to obtain accurate information to answer the problem of this research, that is how the program of planning, service, coaching and controlling in Kindergarten Little Koala Montessori Karawaci Tangerang.

The main data sources (key informants) in this research is the foundation, principals, teachers, administrative staff and parents guardians of learners little koala Montessori. From this source of information will be done some data collection methods such as interviews, documentation and observation to get as much information as possible about "The Management of Kindergarten Students of Little Koala Montessori Karawaci Tangerang”.

\section{Results and Discussion \\ Planning}

In the planning aspect, Kindergarten Little Koala Montessori Karawaci Tangerang applies several plans including; needs analysis, recruitment, selection, orientation, and placement.

The Kindergarten Little Koala Montessori Karawaci Tangerang manager performs needs analysis such as determining the number of students to be accepted, preparing the program of activities, interests and talents, 
facilities and infrastructure, budget and educational personnel available. In addition to performing needs analysis, the Kindergarten Little Koala Montessori Karawaci Tangerang also performs recruitment with several stages of determining the new student admission committee, registration requirements, new student admission committee schedule, acceptance system, online based new student admission committee procedures, determination of capacity and determination of candidates received.

Next related selection. the Kindergarten Little Koala Montessori Karawaci Tangerang party determines the selection stage through test or test (psychotest test, physical test, medical test, academic test, or skill test), and through talent searching ability of learners.

After being declared valid as part of Kindergarten Kindergarten Little Koala Montessori Karawaci Tangerang, supervisors provide orientation for two days through the introduction of Kindergarten Little Koala Montessori Karawaci Tangerang environment, knowing educators, visiting classroom, library, playground and all Kindergarten Little Koala Montessori Karawaci Tangerang facilities.

Kindergarten Little Koala Montessori Karawaci Tangerang also classify learners by gender, age, interests, talents, and abilities. In one class consists of 25 students with guided by 5 educators. So the comparison is 1 educator compared to 8 students.

Based on the findings of research conducted by Miranda, et. al, (2017) Montessori-related schools found that Montessori schools this will allow planning, designing and implementing Smart Learning \& Teaching Environments that will be integrated into the curriculum for kindergarten and primary school; creating situations of learning and teaching that will respect the principles of continuity and balanced growth; building spaces of expression and multi-sensorial experience that will encourage digital game situations mediated by multimedia languages; promoting greater participation and relationship among the different actors of the educational process (teachers, parents and students) that will increase the sense of learning community and the educational co-responsibility.

\section{Coaching}

On the aspect of coaching learners, focus on disciplinary coaching, academic coaching and non-academic coaching.

Fostering discipline, Kindergarten Little Koala Montessori Karawaci Tangerang work together with the team of educators to create a regulation or order book, the book is given to parents. The existence of a regulation that aims to improve the discipline of dress, come on time, maintain personal hygiene and environment, The existence of a notebook case in every class to know how far to understand the discipline. Before entering school there is a complete attribute check and nail check and hair tidiness. Make a pickup card and order a liaison book.

Research conducted by Khachatrya (2015) says that a Montessori classroom the discipline comes through liberty, and the discipline is needed to exercise responsibility. The concept of active discipline gives freedom to the children, which is the key of child's self-formation.

Similarly related to academic activities. The Kindergarten Little Koala Montessori Karawaci Tangerang performs steps for academic coaching among others; run curriculum results that have been decided by the principal of the meeting with the educators and has been acc by the foundation. The curriculum aims to provide increased affective, psychomotor and cognitive stimuli. Academic activities include Math, Science, Phonics, Mathematics, Indonesian and Mandarin. For example: exercise of practical life which is discussing, how to open the door well, how to talk well not shout, how to pour water into the cup.

In addition, the Kindergarten Little Koala Montessori Karawaci Tangerang parties also provide nonacademic guidance. Coaching is not only focused on academics but on the psychological child. The educators also provide assistance to learners to enter in the library, sports, arts and competitions. In addition there are some non-academic activities such as taekwondo, coloring, dancing, futsal, how to perform ablution, prayer, kaji, robotic level lego bricks and communicate directly using English and Mandarin with friends.

In line with the above opinion, the findings of the Kindergarten Little Koala Montessori Karawaci Tangerang school-related research conducted by Melcon et. al, also said that María Montessori schools; institutions that stress the connections between mind and body, movement and cognitive aspects. 


\section{Service}

In the service aspect of learners, focus on counseling and guidance services, library services, canteen services, and health services.

The Kindergarten Little Koala Montessori Karawaci Tangerang provide guidance and counseling services that aim to be able to recognize and develop their potential, overcome learning difficulties and difficulty in adapting, preparing mental and social development. In addition, counseling guidance is also given to inclusive learners who aim to instill confidence, have motivation, can mingle with their friends, and not be discouraged because of lack.

Similarly related to library services, the Kindergarten Little Koala Montessori Karawaci Tangerang provides a library of parents and mini libraries of each class, the library is available a collection of books either textbooks, fiction and nonfiction books, encyclopedias that can be read and borrowed by learners. Also in the library there are also some educative games that can train the emotional power of social, cognitive, psychomotor and affective.

Furthermore, the Kindergarten Little Koala Montessori Karawaci Tangerang Kindergarten management also provides canteen service that aims to fulfill clean, nutritious food so that the health of the students is guaranteed while the Kindergarten Little Koala Montessori Karawaci Tangerang and does not need to roam outside the The Kindergarten Little Koala Montessori Karawaci Tangerang environment to buy food making it easier for the educator to control and supervise learners.

In addition, there are health services facilitated by the Kindergarten Little Koala Montessori Karawaci Tangerang. Health services in the Kindergarten Little Koala Montessori Karawaci Tangerang are named Healthcare for Kindergarten aim to teach children to live healthy like learning to wash their hands before eating. Furthermore, the Kindergarten Little Koala Montessori Karawaci Tangerang also prepares transfortasi services. There are three units of vehicle / car for pickup students.

This is according to the results of research conducted by Carnicellia (2017) that to develop the critical thinking capability of students using a service learning approach; and encourage students to reflect on the skills they have. In a study conducted by Ilknur (2013) it is the Montessori activity of the child but not regarded as an independent value, but as a means of building the personality.

\section{Controlling}

On the controlling aspect, the Kindergarten Little Koala Montessori Karawaci Tangerang performs three aspects of controlling, namely the form of controlling, recording/ reporting and graduates.

The Kindergarten Little Koala Montessori Karawaci Tangerang conducts controlling oversight. Controlling is conducted to oversee the learning process in the form of curriculum, methods and learning techniques, preparation of learning, facilities and school infrastructure.

Neither is the recording and reporting. This recording and reporting activity begins from the moment the learner is accepted until graduation. A progress report in an the Kindergarten Little Koala Montessori Karawaci Tangerang is reported by classroom and verbal educators by meeting face-to-face with parents to discuss the progress of the learner. besides, there are daily report on daily lesson, classroom and parent classroom meetings outside of study time, weekly study report Montessori term, as evaluation and responsibility as education provider.

Furthermore related to graduation and alumni. the Kindergarten Little Koala Montessori Karawaci Tangerang has graduated more than 500 students from the Kindergarten Little Koala Montessori Karawaci Tangerang. In addition, the Kindergarten Little Koala Montessori Karawaci Tangerang relationships with alumni and parents are very close because they always maintain communication and relationship to parents/guardians of learners. When there is an event or event in the Kindergarten Little Koala Montessori Karawaci Tangerang communicate to all parties so tightly established friendship.

This is in accordance with the results of research conducted by Schacter and Booil Jo (2016) that each Montessori "job" communicates clear goals, provides for self-assessment and corrective feedback, and uses manipulatives to learn by doing. 


\section{Conclusion}

In the aspect of student planning, the Kindergarten Little Koala Montessori Karawaci Tangerang apply needs analysis related to class capacity, student and teacher ratios, plan new online learner acceptance online, trace talent ability of learners through academic and skill test and give orientation for two days to learners through the introduction of the environment of the Kindergarten Little Koala Montessori Karawaci Tangerang.

In the aspect of coaching learners do some kind of coaching among others; disciplinary counseling, the Kindergarten Little Koala Montessori Karawaci Tangerang makes a regulatory book of school, student pickup card and parents liaison book. Development of academic activities, including; run the lessons in the classroom. Nonacademic coaching among others; taekwondo, Lego class, coloring, dancing, futsal, how to perform ablution, praying, reciting, and communicating directly in English.

In the service aspect of learners, provide some services such as; provide counseling services to overcome learning difficulties, prepare mental development, and instill confidence, the availability of books in the central library and mini library, and provide canteen service and health services, and prepare three units of transfortation shuttle service for students.

In the supervision aspect, there are daily reports in the daily lesson, weekly study report Montessori term, and building cooperation with graduates.

\section{References}

[1] Michael Armstrong. 2014. Armstrong's Handbook of Human Resource Management Practice. London: Kogan Page Limited.

[2] Adriana Denisa Manea. 2015. Innovation In The Management Of Educational Institutions. International journal Procedia-Social and Behavioral Sciences.

[3] Sara Conde Velez, M Carmen Azaustre Lorenzo. 2017. Leadership: its importance in the management of school coexistence. International Journal Procedia-Social and Behavioral Sciences.

[4] Laura Greta Marin and Diana Rusu. 2015. Management of the Educational Risk Factors in Roma Schools. Journal International Procedia-Social and Behavioral Sciences.

[5] Eric C.K Cheng. 2015. Knowledge Management for School Education. New York: Springer.

[6] Ricky W. Griffin and Gregory Moorhead. 2014. Organizational Behavior, Managing People and Organizations. South-Western: Cengage Learning.

[7] Charles W. L. Hill, Gareth R. Jones and Melissa A. Sc hilling. 2015. Strategic Management An Integrated Approach. Stamford: Cengage Learning, 2015.

[8] David L. Goetsch and Stanley B. Davis. 2014. Quality Management for Organizational Excellence. New Jersey: Pearson Education.

[9] Mie Augier et. al. 2017. Organizational Persistence In The Use of War Gaming And Scenario Planning. International Journal Long Range Planning.

[10] Rasa Laliene, Zieduna Liepe. 2015. R\&D Planning System Approach at Organizational Level. International Journal Procedia-Social and Behavioral Sciences.

[11] Sari Laine et. al. 2016. Significance of Action Plans in the Development of Occupational well-being in the Schools of Finland and Estonia. International Journal Evaluation and Program Planning.

[12] Malgorzata Kolodziejczak. 2015. Coaching Across Organizational Culture. International Journal Procedia Economics and Finance.

[13] Michael S. Carriger. 2015. Problem-Based Learning and Management Development e Empirical and Theoretical Considerations. The International Journal of Management Education.

[14] Maud Besançon et. al. 2015. Influence of School Environment on Adolescents' Creative Potential, Motivation and Well-Being. International Journal Learning and Individual Differences.

[15] Tsung-Ming Liu. 2015. Junior High School Students' Perceptions of Service Learning For Admission to High School, International Journal Procedia-Social and Behavioral Sciences.

[16] Elizabeth B. Miller, George Farkas, Greg J. Duncan. 2016. Does Head Start differentially benefit children with risks targeted by the program's service model?. International Journal Early Childhood Research Quarterly. 
[17] Emma Crawford et. al. 2017. Service learning in developing countries: Student outcomes including personal successes, seeing the world in new ways, and developing as health professionals. Journal of Interprofessional Education \& Practice.

[18] Jannick Demanet and Mieke Van Houtte. 2014. Social-Ethnic School Composition And Disengagement:An Inquiry Into The Perceived Control Explanation. International Journal The Social Science Journal.

[19] Rebecca H. Berger et. al. 2017. Effortful Control And School Adjustment: The Moderating Role Of Classroom Chaos, Journal of Applied Developmental Psychology.

[20] Kimberley J. Bartholomew et. al. 2017. Beware Of Your Teaching Style: A School-Year Long Investigation Of Controlling Teaching And Student Motivational Experiences. International Journal Learning and Instruction.

[21] Christine L. Sheppard MSW et. al. 2015. A Systematic Review of Montessori-Based Activities for Persons With Dementia. International Journal JAMDA.

[22] John Schacter dan Booil Jo. 2016. Improving Low-Income Preschoolers Mathematics Achievement with Math Shelf, a Preschool Tablet Computer Curriculum. International Journal Computers in Human Behavior.

[23] Sergio Miranda, et. al. 2017. A Research Initiative On The Construction Of Innovative Environments For Teaching and Learning. Montessori and Munari Based Psychopedagogical Insights In Computers And Human Behavior For The "New School". International Journal Computers in Human Behavior.

[24] Mariam Khachatryan. 2015. A look at AUA pre-school English Program Through The Lens Of Montessori Pedagogy. International Journal Procedia-Social and Behavioral Sciences.

[25] Paula Bango Melcon et. al. 2017. Dimension Analysis and Architectural Model of BAPNE Classroom for Pre-School and Primary Education, International Journal Procedia-Social and Behavioral Sciences.

[26] Sandro Carnicellia, Karla Boluk. 2017. The Promotion Of Social Justice: Service Learning For Transformative Education. Journal of Hospitality, Leisure, Sport \& Tourism Education.

[27] Filiz Ilknur. 2013. Project-Based Learning In Teaching with the DAF Montessori Method, International Journal Procedia-Social and Behavioral Sciences.

[28] John Schacter dan Booil Jo. 2016. Improving Low-Income Preschoolers Mathematics Achievement with Math Shelf, a Preschool Tablet Computer Curriculum, International Journal Computers in Human Behavior. 